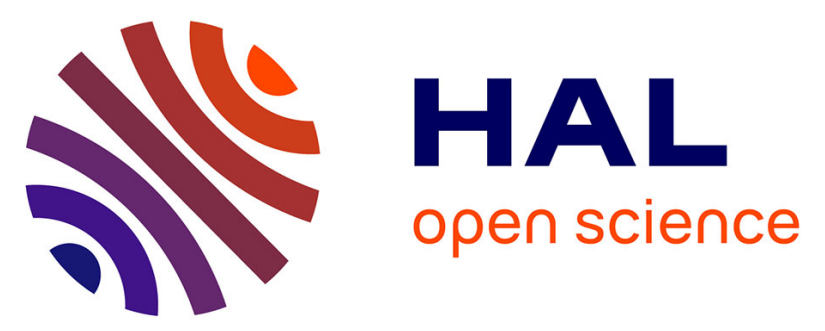

\title{
Simplification of Heavy Matrices by Liquid-Solid Extraction: Part II-How to Separate the LMW, MMW, and HMW Compounds in Asphaltene Fractions for V, $\mathrm{Ni}$, and $\mathrm{S}$ Compounds
}

\author{
German Gascon, Juan Negrin, Victor Montoto, Socrates Acevedo, \\ Charles-Philippe Lienemann, Brice Bouyssière
}

\section{To cite this version:}

German Gascon, Juan Negrin, Victor Montoto, Socrates Acevedo, Charles-Philippe Lienemann, et al. Simplification of Heavy Matrices by Liquid-Solid Extraction: Part II-How to Separate the LMW, MMW, and HMW Compounds in Asphaltene Fractions for V, Ni, and S Compounds. Energy \& Fuels, 2019, 33 (9), pp.8110-8117. 10.1021/acs.energyfuels.9b01511 . hal-02282542

HAL Id: hal-02282542

https: / hal-univ-pau.archives-ouvertes.fr/hal-02282542

Submitted on 18 Dec 2019

HAL is a multi-disciplinary open access archive for the deposit and dissemination of scientific research documents, whether they are published or not. The documents may come from teaching and research institutions in France or abroad, or from public or private research centers.
L'archive ouverte pluridisciplinaire HAL, est destinée au dépôt et à la diffusion de documents scientifiques de niveau recherche, publiés ou non, émanant des établissements d'enseignement et de recherche français ou étrangers, des laboratoires publics ou privés. 
Simplification of heavy matrices by liquid-solid extraction: part II - how to separate the LMW, MMW and HMW compounds in asphaltene fractions for $\mathrm{V}$, Ni and $\mathrm{S}$ compounds

German Gascon $^{\dagger, \ddagger \S}$, Juan Negrín ${ }^{\dagger}$, Victor G. Montoto ${ }^{\ddagger}$, Socrates Acevedo ${ }^{\S}$, Charles-Philippe Lienemann", Brice Bouyssiere*

${ }^{\dagger}$ PDVSA Intevep, Apartado 76343, Caracas 1070-A, Venezuela

CNRS/ Univ pau \& pays ADOUR/ E2S UPPA, Institut des Sciences Analytiques et de PhysicoChimie Pour L'environnement et les Materiaux, UMR5254, Helioparc- 2 Avenue du Président Angot 64000, Pau, France

${ }^{\S}$ UCV, Facultad de Ciencias, Escuela de Química, Caracas, 1053, Venezuela "IFP Energies Nouvelles, Rond-point de l'échangeur de Solaize, BP 3, 69360 Solaize, France 


\begin{abstract}
A method of sequential liquid-solid extraction (leaching) has been developed to extract the $\mathrm{V}, \mathrm{Ni}$ and S compounds present in asphaltenes $\left(n-C_{7}\right)$ according to their molecular weight distribution. For the high molecular weight (HMW) compounds, two new families of compounds were extracted, labeled HMW1 and HMW2, where the latter was smaller than HMW1, and together represented approximately $85 \%$ of the asphaltene mass according to the mass balance obtained after the extractions. The compounds associated with HMW1 were asphaltenes that were insoluble in hot dimethylformamide (DMF), while the compounds associated with HMW2 were soluble in DMF but insoluble in the second leaching step based on hot acetone. The third family of obtained compounds was the medium molecular weight (MMW) compounds, which were soluble in hot acetone but insoluble in acetonitrile $(\mathrm{ACN})$. The last fraction to be obtained was the low molecular weight (LMW) compounds, which were soluble in ACN. The results reported here represent a new method that allows the extraction of different types of aggregated asphaltenes according to their molecular weights. With respect to the temperature and number of extraction steps, it was observed that an increase in both parameters increased the extraction efficiency.
\end{abstract}




\section{INTRODUCTION}

As it is well known, the term asphaltene covers a wide variety of substances with different structures but similar properties (polarity, size, molecular weight, etc.) ${ }^{1}$ that exist in crude oil and tend to precipitate when a light nonpolar solvent is added in excess. Micthell and Speight ${ }^{2}$ determined the relationship between the percentage of asphaltenes that precipitate and the solubility parameters of the paraffinic, iso-paraffinic and olefinic solvents that were used. The molecular state of these substances in crude oil was initially thought to be soluble or dispersed due to the peptization achieved by the resins (less polarity substances), which acted as surfactants. ${ }^{3-5}$ However, due to the reversibility of the precipitation-dissolution process, which is not characteristic of colloidal particles stabilized by surfactants, ${ }^{6}$ the behavior in solution and the high molecular weights observed by various techniques (VPO, Gel Permeation Chromtography (GPC), etc.), ${ }^{7}$ this model has been discarded and replaced by the model proposed by Dickie and Yen $^{7,8}$ (later modified by Mullins ${ }^{9,10}$ ). Recently Gray et al. ${ }^{11}$ proposed a models with a macrostructure or supramolecular assembly (nanoaggregates) where asphaltenes are kepted in solution due to the different configurations that these substances can adopt. Regarding the size of these nanoaggregates, some studies have mentioned proper colloidal particle sizes $(>1 \mathrm{~nm})$ with average sizes between 5 and $10 \mathrm{~nm}$ but less than $20 \mathrm{~nm}$, even in dilute solutions, ${ }^{12,13}$ although different critical nanoaggregation concentrations (CNCs) have been reported, ${ }^{14-18}$ possibly due to solvent effects.

Presence and distribution of $\mathrm{V}$ and $\mathrm{Ni}$ in crude oil. $\mathrm{Ni}$ and $\mathrm{V}$ are by far the most abundant metals in crude oil. ${ }^{19}$ The predominance of $\mathrm{Ni}$ and $\mathrm{V}$ compounds compared to other organometallic compounds is a consequence of their highly stable N-V or N-Ni bonds and their favorable electron configurations, among other factors. ${ }^{20,21}$ Studies by X-ray absorption fine 
structure (XAFS) spectroscopy have shown that Ni and V form coordination compounds with tetrapyrrolic ring-type porphyrins. ${ }^{22,23}$ Because of their high boiling points, these compounds are concentrated in vacuum residues $(99 \%),{ }^{24}$ and due to their solubilities, they are principle components in resins and asphaltenes (99\%). ${ }^{25-27}$ Additionally, different studies by gel permeation chromatography with inductively coupled plasma mass spectrometry (GPC-ICP MS $)^{24-27}$ have shown on many different heavy fractions and since more than 10 years that these compounds have a wide molecular weight distribution and typically contain high molecular weight (HMW / >10000 Da) and medium molecular weight (MMW / 1000-10000 Da) compounds. The mass of these fractions are expressed as weight in Da according to polystyrene standard calibration.

However, Mass Spectrometry (MS) ${ }^{28-31}$ has identified mainly low molecular weight $(\mathrm{LMW} /<$ $1000 \mathrm{Da}$ ) compounds ${ }^{24,27}$ in comparison with MMW and HMW compounds that are observed by GPC-ICP MS and this can be explained with the difficulty in ionizing molecules trapped in aggregates by molecular MS. ${ }^{32}$ Recently, Ramirez-Pradilla et al. ${ }^{33}$ described the identification of more than 300 petroporphyrins in acetonitrile $(\mathrm{ACN})$ extracts of crude oil. According to this study, the ACN extracts corresponded to less than $10 \%$ of the $\mathrm{V}$ present in crude oil, reflecting the work that remains for a complete identification of petroporphyrins by molecular mass spectrometry (MS).

Association of $\mathbf{V}$ and $\mathrm{Ni}$ compounds with asphaltenes. Because a high percentage of the $\mathrm{V}$ and Ni compounds that are present in crude oil, resins and asphaltenes do not absorb in the UVVis range, a hypothesis was formulated that a portion of the $\mathrm{V}$ and $\mathrm{Ni}$ compounds are metalloporphyrins joined via coordination bonds with atoms that have unshared electron pairs, such as the $\mathrm{N}, \mathrm{O}$ and $\mathrm{S}$ heteroatoms present in asphaltenes with large nanoaggregate 
structures. ${ }^{11,34}$ Another possibility could be that the V and Ni compounds are trapped in asphaltene macrostructures or nanoaggregates without specific metal-heteroatom interactions. ${ }^{7,35,36}$ In both cases, these configurations would not exhibit absorption in the UV-Vis range, which would explain the MMW and HMW compound distribution observed by GPC-ICP MS for these types of compounds. ${ }^{24,27}$

Role of GPC-ICP MS. Due to the limitations of molecular MS for the direct and quantitative identification of crude oil compounds with HMW- and MMW-type nanoaggregates or macrostructures, GPC-ICP MS constitutes, from our point of view, an interesting tool for studying the S, V and Ni compounds present in these samples. Despite the criticisms to which the GPC technique is subjected, ${ }^{37,38}$ coupling GPC with ICP MS enables the identification of the relative sizes associated with the various $\mathrm{V}, \mathrm{Ni}$ and $\mathrm{S}$ compounds present in either crude oil or some of its products (distillates, ${ }^{24}$ residues, ${ }^{24}$ and SARA fractions ${ }^{27}$ ). In fact, the data obtained by GPC-ICP MS, especially for MMW and HMW compounds, which are difficult to identify by molecular MS due to their poor ionization efficiencies, ${ }^{39}$ have been broadly supported by theoretical models regarding the molecular state of asphaltenes in crude oil or solution. ${ }^{8-11,32}$

Separation of $\mathrm{V}$ and $\mathrm{Ni}$ compounds according to their size or molecular weight. Various methods have been developed using either Soxhlet extraction or chromatography with a packed column to separate the different $\mathrm{V}$ and $\mathrm{Ni}$ compounds in crude oil (not necessarily by separation into different MW fractions). ${ }^{40-45}$ However, due to the strong adsorption of asphaltenes onto commonly used adsorbents (alumina, silica gel, etc.), these methods regularly exhibit poor separation. ${ }^{46}$ A liquid-liquid extraction method for the separation of HMW, MMW and LMW compounds in maltenes (including S-, V- and Ni-containing compounds) was previously developed and had excellent results. ${ }^{47}$ Based on this method, a similar approach focused on 
aphaltene is proposed in this work. Specifically, a liquid-solid extraction method for the separation of V and Ni compounds present in asphaltenes is developed based on the Galimov separation of petroporphyrines ${ }^{48}$ with the advantage of obtaining GPC-ICP MS profiles to evaluate the efficiency of such fractionation.

\section{EXPERIMENTAL SECTION}

Instrumentation. A high-performance liquid chromatograph (HPLC) (UltiMate 3000, Dionex, Amsterdam, The Netherlands) was used for the GPC separation and was coupled with an ICP high-resolution MS (HR-MS). The detailed conditions for ICP-HR-MS detection have been previously reported ${ }^{27}$ and are summarized here. An ICP-HR-MS instrument (Element XR, Thermo Scientific, Bremen, Germany) operating at a resolution of 4000 was used. The ICP-HRMS was equipped with an interface based on a microflow total-consumption nebulizer without a drain and was thermoregulated at $60{ }^{\circ} \mathrm{C}$ to minimize signal suppression and increase the sensitivity by a factor of $3-4 .{ }^{49}$ An oxygen flow of $0.08 \mathrm{~mL} / \mathrm{min}$ was continuously added to the nebulizer gas flow (Ar) to avoid the deposition of carbon onto the cones.

Samples, reagents, and materials. For this work, an $8^{\circ}$ API Venezuelan crude oil sample provided by PDVSA Intevep was used. n-Heptane was used for asphaltene precipitation, and methanol (MeOH), ACN, 1-propanol, acetone, methyl-tert-butyl-ether (MTBE), ethyl acetate (EA), acetylacetone, dimethylformamide (DMF) and diethylamine were used for the liquid-solid extractions. Tetrahydrofuran (THF) was used to dilute the samples and for the GPC experiments. The separations were carried out using a guard column $(4.6 \times 30 \mathrm{~mm})$ and three Waters (Waters Corporation, Milford, MA) styrene-divinylbenzene gel permeation columns (7.8 mm inner diameter $\times 300$ 
mm length, Styragel) connected in series in the following order: HR4, HR2, HR0.5. The mass obtained are expressed as weight in Da according to polystyrene standard calibration. This calibration is also checked daily with commercial porphyrins with known mass ${ }^{27}$. All solvents were HPLC grade with a 95\% or greater purity and obtained from Sigma-Aldrich.

Obtaining asphaltenes. Initially, $50 \mathrm{~g}$ of crude oil was heated at $80{ }^{\circ} \mathrm{C}$ in an oven for 24 hours to eliminate the presence of volatile compounds that could interfere with the mass balances. The crude oil was then mixed with n-heptane in a ratio of 60:1 heptane:crude oil to assure complete asphaltene precipitation. This mixture was placed in an ultrasonic bath for 10 minutes, followed by 1 hour of agitation with a magnetic stirrer at $60{ }^{\circ} \mathrm{C}$. To obtain the asphaltenes, the mixture was filtered twice with filter paper (pore size $2.5 \mu \mathrm{m}$, Whatman) and washed with hot heptane.

Solvent extraction. First, $0.50 \pm 0.01 \mathrm{~g}$ of the asphaltenes was weighed, placed in a flask with $150 \mathrm{~mL}$ of solvent to maintain a ratio of 300:1 solvent:asphaltene, and heated to reflux for 1 hour with agitation using a magnetic stirrer. The resulting mixture was filtered and separated into soluble asphaltenes (AS) and insoluble asphaltenes (AI) by filtration with filter paper (pore size $2.5 \mu \mathrm{m}$, Whatman). The same procedure was repeated for all the solvents that were evaluated. GPC-ICP MS detection. Each sample was diluted 200-fold with THF for GPC-ICP-HRMS detection. A $20 \mu \mathrm{L}$ sample was injected and isocratically eluted with a THF flow rate of 1 $\mathrm{mL} / \mathrm{min}$ for 120 minutes. A splitter was used after the columns to obtain a low-flow outlet (50 $\mu \mathrm{L} / \mathrm{min}$ ) to feed the ICP-HR-MS. A custom-made Microsoft Excel spreadsheet was used to deconvolute the chromatograms by summing the Gaussian curves.

\section{RESULTS AND DISCUSSION}


Part I. Solvent extractions. The amounts of AS and AI obtained with each solvent are expressed as a percentage of the total asphaltenes in Table 1, along with the values of several physical characteristics for each solvent used. No correlation was found between the parameters proposed in Table 1 and the percentages of the AS and AI extractions, which shows the complexity of the asphaltene solubility phenomenon. It is interesting to observe the GPC-ICPHR-MS profile of the $\mathrm{V}$ compounds ( $\mathrm{Ni}$ and $\mathrm{S}$ compounds are not shown here) for each solvent are shown in Figures 1 and 2, as this allows to distinguish the type of V compounds (HMW, MMW or LMW) extracted by each solvents. As seen in both figures, several specific solvents are particularly efficient at extracting LMW compounds with different yields in the following order: acetone $>$ ACN $>1$-propanol $>>$ acetic acid (see Figure 1). Similarly, there are solvents for which the extraction of a larger, but less specific portion of the asphaltene fraction can be observed, primarily for the MMW compounds and, to a lesser extent, the HMW compounds in the following yield order: DMF $>$ acetylacetone $>$ EA $>$ MTBE. Finally, diethyl amine dissolved a large proportion of the HMW compounds (see Figure 2).

Effects of temperature and number of extractions. To evaluate the influence of the temperature, an extraction with DMF at room temperature was performed and compared with an extraction with hot DMF (below the boiling point: $153{ }^{\circ} \mathrm{C}$ ). As seen in Figure 3, the temperature has a very noticeable effect on the solubilization of asphaltenes, showing that the extraction process can be endothermic when the solvent is "bad" or "poor" in terms of solubility in comparison with other "good" solvents (THF, Dichloromethane, Benzene, Toluene, Xylene, etc.). This behavior has been previously reported by Galimov. ${ }^{48}$ On the other hand, the effect of 4 successive extractions was studied. The results are shown in Figure 4. As expected, with an increasing number of extractions, a decrease in the amount of extracted $\mathrm{V}$ and $\mathrm{Ni}$ compounds is 
observed. This decrease is more rapid for the MMW and LMW compounds in comparison to the HMW compounds (Figure 4). Subsequently, in extractions 3 and 4, the profile changes show that only HMW compounds are removed, suggesting a difference in the solubility behavior of these compounds in comparison with that of the MMW and LMW compounds. This can be compared with the high removal percentages observed for DMF and acetylacetone (solvents with high boiling points), as shown in Table 1.

Part II. Sequential extraction. Optimization of the extraction. Considering the results shown in Figures 1 and 2, various sequential separation schemes were evaluated. According to these tests, the key results for separating different classes of molecular weight compounds are presented in Figure 5. Here, the total results of 3 successive extractions for the V compounds (Ni and $\mathrm{S}$ compounds are not shown here) are shown, allowing the separation of 4 different portions of asphaltene. The scheme begins with the whole asphaltene mixture (Figure 5a). Then, the use of hot DMF as the first extractant allows the separation of an insoluble monomodal HMW fraction of asphaltenes (Figure 5b), labeled HMW1. The resulting soluble fraction (Figure 5c) clearly shows a trimodal distribution of the molecular weights, suggesting that another family of HMW compounds requires further extraction. From this soluble fraction, it was then possible to separate the remaining HMW compounds (referred to herein as HMW2), which have lower molecular weights than HMW1, as can be discerned from the retention time, as a monomodal fraction by using hot acetone (Figure 5d), in which HMW2 is insoluble. In the resulting soluble fraction obtained from this second extraction (Figure 5e), the HMW compounds are gone, and a bimodal profile comprising mainly the MMW and LMW compounds remains. These two families of compounds can be separated by using hot ACN to obtain an insoluble fraction composed entirely of MMW compounds (Figure 5f). The residual soluble fraction in ACN 
(Figure $5 \mathrm{~g}$ ) still has a bimodal distribution with a small percentage of MMW compounds and a large percentage of LMW compounds being found in this asphaltene fraction. The scheme of the extraction proposed in this article can separate the initial asphaltene fraction into four individual fractions with specific molecular weights as monitored by GPC-ICP-HR-MS.

The total results from monitoring the complete set of $\mathrm{V}, \mathrm{Ni}$ and $\mathrm{S}$ compounds of the extraction strategy presented above applied to asphaltene from a Venezuelan extra-heavy crude oil sample are shown in Figure 6. The separation of the V, Ni and S compounds present in asphaltene fractions according to their molecular weights is achieved, which has not been previously reported. The mass balance shows that approximately $70-80 \%$ of the $\mathrm{V}$ and $\mathrm{Ni}$ compounds are present in the HMW fractions (Figure 7), which can be interpreted as $\mathrm{V}$ and $\mathrm{Ni}$ compounds being integrated into the macrostructure of the asphaltenes and thereby eluting in the HMW region of the GPC chromatogram. This behavior can be explained by the tendency of asphaltenes to trap compounds $s^{35,36}$ or the probability of forming coordination bonds between the metals and electron donor atoms $(\mathrm{S}, \mathrm{N}$ and $\mathrm{O})$ of the asphaltenes. ${ }^{11,34}$

Regarding the nature of the specific separation observed, the separation cannot be simply explained in terms of the solvent polarity as solvents with similar dipolar moments $(\mathrm{MeOH}, \varepsilon=$ 33; ACN, $\varepsilon=37$; and DMF, $\varepsilon=38$ ) show different removal percentages. More likely, the temperature and other generic conditions, as well as the interactions between the solvent and the whole macrostructure or nanoaggregate, have a larger impact than any specific interaction between individual compounds, such as solvent-metal interactions, as previously suggested. ${ }^{47}$ This explains the reconstruction of the initial total asphaltene GPC chromatogram from the information obtained from each fraction (Figure 5). As was previously shown ${ }^{39}$ for reinjection of 
the HMW and MMW GPC fractions, we can demonstrate that this extraction scheme extracts nanoaggregates (mainly HMW1 and HMW2) that are stable rather than individual compounds.

Complete fractionation method. According to a previous paper ${ }^{47}$ that presented a fractionation step for maltenes, Figure 8 shows the mass balance of the complete fractionation protocol for maltene (previous study ${ }^{47}$ ) and asphaltene (this study) extraction. According to all the different steps of the extraction procedure, a mass balance of between 95 and $97 \%$ obtained for the Ni, V and $\mathrm{S}$ compounds shows that almost all the Ni, V and $\mathrm{S}$ compounds can be extracted with this protocol. Sulfur has a completely different behavior compared to that of V and $\mathrm{Ni}$ showing that sulfur is not mainly driving the aggregation/sequestration of $\mathrm{V}$ and $\mathrm{Ni}$. Regarding Ni and V, similar behavior is obtained except for their LMW extracts, for which the Ni compounds consistently have a lower percentage than the V compounds. This can explain why, in most molecular MS studies, ${ }^{33} \mathrm{~V}$ petroporphyrins have primarily been identified because the Ni and V compounds in nanoaggregates associated with the HMW fraction are more difficult to ionize. ${ }^{39}$

\section{CONCLUSIONS}

The use of liquid-solid extraction as an adequate methodology for the separation of the V, $\mathrm{Ni}$ and S compounds present in asphaltenes based on their molecular weights is reported for the first time. An optimized extraction procedure establishing a sequence based on the choice of solvent, temperature, and methodology is proposed for the separation of these compounds. For example, an increase in temperature was found to improve the extraction of asphaltenes for a given solvent due to the complex endothermic process of solubilization. Additionally, the effectiveness of the overall extraction is determined by the number of extraction steps. With 
respect to the methodology, sequential extractions were the most successful for the proposed goal. As a result, it was found that at least $70-80 \%$ of the $\mathrm{V}, \mathrm{Ni}$ and $\mathrm{S}$ compounds present in asphaltenes are associated with the HMW fraction, typically containing nanoaggregates or macrostructures. This result seems to be in agreement with the results of previous techniques in which $90 \%$ of the asphaltenes form aggregates. ${ }^{17}$ Likewise, the results suggest that the solventnanoaggregate interactions and the temperature play the most important roles in the separation process. These results also demonstrate that the use of a GPC-ICP-HR-MS technique is a very effective tool for monitoring separation methods, especially for $\mathrm{V}, \mathrm{Ni}$ and $\mathrm{S}$ compounds.

This new methodology, combined with the results of our previous work, ${ }^{47}$ will allow the fractionation of complex petroleum samples into different families of compounds or nanoaggregates based on their solubilities.

\section{AUTHOR INFORMATION}

\section{Corresponding author}

*Brice.bouyssiere@univ-pau.fr

\section{NOTES}

The authors declare no competing financial interest.

\section{ACKNOWLEDGMENTS}

The financial support of the Conseil Régional d'Aquitaine (20071303002PFM) and FEDER (31486/08011464) is acknowledged. This work is a collaboration among the University of Pau (UPPA), Total, IFP Energies Nouvelles, PDVSA INTEVEP, and the Central University of 
Venezuela (UCV) on behalf of the PCP project "Metalopetroleomic" financially supported by the MAE. 


\section{REFERENCES}

(1) Linton, L. A. On the technical analysis of asphaltum. J. Am. Chem. Soc. 1894, 16, 80922.

(2) Mitchell, D. L.; Speight, J. G. The solubility of asphaltenes in hydrocarbon solvents. Fuel 1973, 52, 149-52.

(3) Nellensteyn, F. I. The colloidal structure of bitumens. In The Science of Petroleum; Dunstan, A. E., Ed.; Oxford University Press: London, UK, 1938; pp 1-4.

(4) Pfeiffer, J. P.; Saal, R. N. J. Asphaltic bitumen as colloid system. J. Phys. Chem. 1940, $44,139-49$.

(5) Swanson, J. M. A contribution to the physical chemistry of the asphalts. J. Phys. Chem. 1942, 46, 141-50.

(6) Porte, G.; Zhou, H.; Lazzeri, V. Reversible description of asphaltene colloidal association and precipitation. Langmuir 2003, 19, 40-7.

(7) Dickie, J. P.; Yen, T. F. Macrostructures of the asphaltic fractions by various instrumental methods. Anal. Chem. 1967, 39, 1847-52.

(8) Yen, T. F.; Erdman, J. G.; Pollack, S. S. Investigation of the structure of petroleum asphaltenes by X-ray diffraction. Anal. Chem. 1961, 33, 1587-94.

(9) Mullins, O. C. The modified yen model. Energy Fuels 2010, 24, 2179-207.

(10) Mullins, O. C.; Sabbah, H.; Eyssautier, J.; Pomerantz, A. E.; Barré, L.; Andrews, A. B.; Ruiz-Morales, Y.; Mostowfi, F.; McFarlane, R.; Goual, L.; Lepkowicz, R.; Cooper, T.; Orbulescu, J.; Leblanc, R. M.; Edwards, J.; Zare, R. N. Advances in asphaltene science and the Yen-Mullins model. Energy Fuels 2012, 26, 3986-4003. 
(11) Gray, M. R.; Tykwinski, R. R.; Stryker, J. M.; Tan, X. Supramolecular assembly model for aggregation of petroleum asphaltenes. Energy Fuels 2011, 25, 3125-34.

(12) Yarranton, H. W.; Ortiz, D. P.; Barrera, D. M.; Baydak, E. N.; Barré, L.; Frot, D.; Eyssautier, J.; Zeng, H.; Xu, Z.; Dechaine, G.; Becerra, M.; Shaw, J. M.; McKenna, A. M.; Mapolelo, M. M.; Bohne, C.; Yang, Z.; Oake, J. On the size distribution of self-associated asphaltenes. Energy Fuels 2013, 27, 5083-106.

(13) Eyssautier, J.; Frot, D.; Barré, L. Structure and dynamic properties of colloidal asphaltene aggregates. Langmuir 2012, 28, 11997-2004.

(14) Evdokimov, I. N.; Eliseev, N. Y.; Akhmetov, B. R. Assembly of asphaltene molecular aggregates as studied by near-UV/visible spectroscopy. J. Pet. Sci. Eng. 2003, 37, 145-52.

(15) Andreatta, G.; Bostrom, N.; Mullins, O. C. High-Q ultrasonic determination of the critical nanoaggregate concentration of asphaltenes and the critical micelle concentration of standard surfactants. Langmuir 2005, 21, 2728-36.

(16) Andersen, S. I.; Speight, J. G. Observations on the critical micelle concentration of asphaltenes. Fuel 1993, 72, 1343-4.

(17) Yarranton, H. W.; Alboudwarej, H.; Jakher, R. Investigation of asphaltene association with vapor pressure osmometry and interfacial tension measurements. Ind. Eng. Chem. Res. 2000, 39, 2916-24

(18) Acevedo, S.; Ranaudo, M. A.; Pereira, J. C.; Castillo, J.; Fernández, A.; Pérez, P.; Caetano, M. Thermo-optical studies of asphaltene solutions: evidence for solvent-solute aggregate formation. Fuel 1999, 78, 997-1003.

(19) Speight, J. G. The Chemistry and Technology of Petroleum; CRC Press: Boca Raton, FL, 1999. 
(20) Lewan, M. D.; Maynard, J. B. Factors controlling enrichment of vanadium and nickel in the bitumen of organic sedimentary rocks. Geochim. Cosmochim. Acta 1982, 46, 2547-60.

(21) Quirke, J. M. E. Rationalization for the predominance of nickel and vanadium porphyrins in the geosphere. In Metal Complexes in Fossil Fuels. Geochemistry, Characterization and Processing; Filby, R. H.; Branthaver, J. F., Eds.; American Chemical Society: Washington, DC, 1987; pp 74-83.

(22) Goulon, J.; Retournard, A.; Friant, P.; Goulon-Ginet, C.; Berthe, C.; Muller, J.-F.; Poncet, J.-L.; Guilard, R.; Escalier, J.-C.; Neff, B. Structural characterization by X-ray absorption spectroscopy (EXAFS/XANES) of the vanadium chemical environment in Boscan asphaltenes. J. Chem. Soc., Dalton Trans. 1984, 6, 1095-1103.

(23) Miller, J. T.; Fisher, R. B.; van der Eerden, A. M. J.; Koningsberger, D. C. Structural determination by XAFS spectroscopy of non-porphyrin nickel and vanadium in maya residuum, hydrocracked residuum, and toluene-insoluble solid. Energy Fuels 1999, 13, 719-27.

(24) Desprez, A.; Bouyssiere, B.; Arnaudguilhem, C.; Krier, G.; Vernex-Loset, L.; Giusti, P. Study of the size distribution of sulfur, vanadium, and nickel compounds in four crude oils and their distillation cuts by gel permeation chromatography inductively coupled plasma highresolution mass spectrometry. Energy Fuels 2014, 28, 3730-7.

(25) Biggs, W. R.; Fetzer, J. C.; Brown, R. J.; Reynolds, J. G. Characterization of vanadium compounds in selected crudes I. Porphyrin and non-porphyrin separation. Liq. Fuels Technol. $1985,3,397-421$.

(26) Park, J.-I.; Al-Mutairi, A.; Marafie, A. M. J.; Yoon, S.-H.; Mochida, I.; Ma, X. The characterization of metal complexes in typical Kuwait atmospheric residues using both GPC coupled with ICP-MS and HT GC-AED. J. Ind. Eng. Chem. 2016, 34, 204-12. 
(27) Gascon, G.; Vargas, V.; Feo, L.; Castellano, O.; Castillo, J.; Giusti, P.; Acavedo, S.; Lienemann, C.-P.; Bouyssiere, B. Size distributions of sulfur, vanadium, and nickel compounds in crude oils, residues, and their saturate, aromatic, resin, and asphaltene fractions determined by gel permeation chromatography inductively coupled plasma high-resolution mass spectrometry. Energy Fuels 2017, 31, 7783-8.

(28) McKenna, A. M.; Purcell, J. M.; Rodgers, R. P.; Marshall, A. G. Identification of vanadyl porphyrins in a heavy crude oil and raw asphaltene by atmospheric pressure photoionization fourier transform ion cyclotron resonance (FT-ICR) mass spectrometry. Energy Fuels 2009, 23, 2122-8.

(29) Qian, K.; Mennito, A. S.; Edwards, K. E.; Ferrughelli, D. T. Observation of vanadyl porphyrins and sulfur-containing vanadyl porphyrins in a petroleum asphaltene by atmospheric pressure photonionization Fourier transform ion cyclotron resonance mass spectrometry. Rapid Commun. Mass Spectrom. 2008, 22, 2153-60.

(30) Rodgers, R. P.; Hendrickson, C. L.; Emmett, M. R.; Marshall, A. G.; Greaney, M.; Qian, K. Molecular characterization of petroporphyrins in crude oil by electrospray ionization Fourier transform ion cyclotron resonance mass spectrometry. Can. J. Chem. 2001, 79, 546-51.

(31) McKenna, A. M.; Williams, J. T.; Putman, J. C.; Aeppli, C.; Reddy, C. M.; Valentine, D. L.; Lemkau, K. L.; Kellermann, M. Y.; Savory, J. J.; Kaiser, N. K.; Marshall, A. G.; Rodgers, R. P. Unprecedented ultrahigh resolution FT-ICR mass spectrometry and parts-per-billion mass accuracy enable direct characterization of nickel and vanadyl porphyrins in petroleum from natural seeps. Energy Fuels 2014, 28, 2454-64. 
(32) Silva, H. S.; Alfarra, A.; Vallverdu, G.; Bégué, D.; Bouyssiere, B.; Baraille, I. Impact of H-bonds and porphyrins on asphaltene aggregation as revealed by molecular dynamics simulations. Energy Fuels 2018, 32, 11153-64.

(33) Ramírez-Pradilla, J. S.; Blanco-Tirado, C.; Hubert-Roux, M.; Giusti, P.; Afonso, C.; Combariza, M. Y. Comprehensive petroporphyrin identification in crude oils using highly selective electron transfer reactions in MALDI-FTICR-MS. Energy Fuels 2019. doi: 10.1021/acs.energyfuels.8b04325.

(34) Dechaine, G. P.; Gray, M. R. Chemistry and association of vanadium compounds in heavy oil and bitumen, and implications for their selective removal. Energy Fuels 2010, 24, $2795-808$

(35) Acevedo, S.; Guzmán, K.; Labrador, H.; Carrier, H.; Bouyssiere, B.; Lobinski, R. Trapping of metallic porphyrins by asphaltene aggregates: a size exclusion microchromatography with high-resolution inductively coupled plasma mass spectrometric detection study. Energy Fuels 2012, 26, 4968-77.

(36) Acevedo, S.; Cordero T., J. M.; Carrier, H.; Bouyssiere, B.; Lobinski, R. Trapping of paraffin and other compounds by asphaltenes detected by laser desorption ionization-time of flight mass spectrometry (LDI-TOF MS): role of A1 and A2 asphaltene fractions in this trapping. Energy Fuels 2009, 23, 842-8.

(37) Behrouzi, M.; Luckham, P. F. Limitations of size-exclusion chromatography in analyzing petroleum asphaltenes: a proof by atomic force microscopy. Energy Fuels 2008, 22, $1792-8$ 
(38) Mullins, O. C.; Martínez-Haya, B.; Marshall, A. G. Contrasting perspective on asphaltene molecular weight. This comment vs the overview of A. A. Herod, K. D. Bartle, and R. Kandiyoti. Energy Fuels 2008, 22, 1765-73.

(39) Putman, J. C.; Sama, S. G.; Barrère-Mangote, C.; Rodgers, R. P.; Lobinski, R.; Marshall, A. G.; Bouyssière, B.; Giusti, P. Analysis of petroleum products by gel permeation chromatography coupled online with inductively coupled plasma mass spectrometry and offline with fourier transform ion cyclotron resonance mass spectrometry. Energy Fuels 2018, 32, $12198-204$.

(40) Ysambertt, F.; Marquez, N.; Rangel, B.; Bauza, R.; De La Cruz, C. Isolation and characterization of metalloporphyrins from a heavy crude oil by soxhlet adsorption chromatography and HPLC-SEC. Sep. Sci. Technol. 1995, 30, 2539-50.

(41) Márquez, N.; Ysambertt, F.; De La Cruz, C. Three analytical methods to isolate and characterize vanadium and nickel porphyrins from heavy crude oil. Anal. Chim. Acta 1999, 395, $343-9$.

(42) Xu, H.; Yu, D.; Que, G. Characterization of petroporphyrins in Gudao residue by ultraviolet/visible spectrophotometry and laser desorption ionization-time of flight mass spectrometry. Fuel 2005, 84, 647-52.

(43) Gao, Y. Y.; Shen, B. X.; Liu, J. C. The structure identification of vanadium porphyrins in venezuela crude oil. Energy Sources, Part A 2012, 34, 2260-7.

(44) Zhao, X.; Liu, Y.; Xu, C.; Yan, Y.; Zhang, Y.; Zhang, Q.; Zhao, S.; Chung, K.; Gray, M. R.; Shi, Q. Separation and characterization of vanadyl porphyrins in venezuela orinoco heavy crude oil. Energy Fuels 2013, 27, 2874-82. 
(45) Liu, T.; Lu, J.; Zhao, X.; Zhou, Y.; Wei, Q.; Xu, C.; Zhang, Y.; Ding, S.; Zhang, T.; Tao, X.; Ju, L.; Shi, Q. Distribution of vanadium compounds in petroleum vacuum residue and their transformations in hydrodemetallization. Energy Fuels 2015, 29, 2089-96.

(46) Vargas, V.; Castillo, J.; Ocampo Torres, R.; Bouyssiere, B.; Lienemann, C.-P. Development of a chromatographic methodology for the separation and quantification of $\mathrm{V}, \mathrm{Ni}$ and S compounds in petroleum products. Fuel Process. Technol. 2017, 162, 37-44.

(47) Gascon, G.; Negrin, J.; Garcia-Montoto, V.; Acevedo, S.; Lienemann, C.-P.; Bouyssiere, B. Simplification of heavy matrices by liquid-liquid extraction: part I- how to separate LMW, MMW, and HMW compounds in maltene fractions of $\mathrm{V}, \mathrm{Ni}$, and $\mathrm{S}$ compounds. Energy Fuels 2019, 33, 1922-7.

(48) Galimov, R. A.; Krivonozhkina, L. B.; Abushaeva, V. V.; Romanov, G. V. Extraction of vanadylporphyrins from petroleum asphaltenes. Neftekhimiya 1993, 33, 552-6.

(49) Caumette, G.; Lienemann, C.-P.; Merdrignac, I.; Paucot, H.; Bouyssiere, B.; Lobinski, R. Sensitivity improvement in ICP MS analysis of fuels and light petroleum matrices using a microflow nebulizer and heated spray chamber sample introduction. Talanta 2009, 80, 1039-43. 


\section{TABLES}

Table 1. Mass percentages of the AS and AI fractions and several physical characteristics of the solvents that were evaluated.

\begin{tabular}{lcccc}
\hline \multicolumn{1}{c}{ Solvent } & $\%$ AS & $\%$ Al & $\begin{array}{c}\text { Dielectric } \\
\text { constant }(\varepsilon)\end{array}$ & $\begin{array}{c}\text { Hansen's solubility } \\
\text { parameter } \delta \\
(\mathrm{MPa})^{1 / 2}\end{array}$ \\
\hline Methanol (MeOH) & $<0.5$ & 99.5 & 33 & 29.6 \\
Acetic acid & 2 & 98 & 6.2 & 21.4 \\
Acetonitrile (ACN) & 2 & 98 & 37 & 24.4 \\
1-Propanol & 2 & 98 & 20 & 24.6 \\
Acetone & 3 & 97 & 21 & 19.9 \\
Methyl-tert-butyl-ether & 5 & 95 & - & - \\
(MTBE) & & & & 18.1 \\
Ethyl acetate (EA) & 12 & 88 & 6.0 & - \\
Acetylacetone & 36 & 64 & - & 24.9 \\
Dimethylformamide (DMF) & 38 & 62 & 38 & - \\
Diethylamine & 60 & 40 & - & \\
\hline
\end{tabular}




\section{FIGURES}

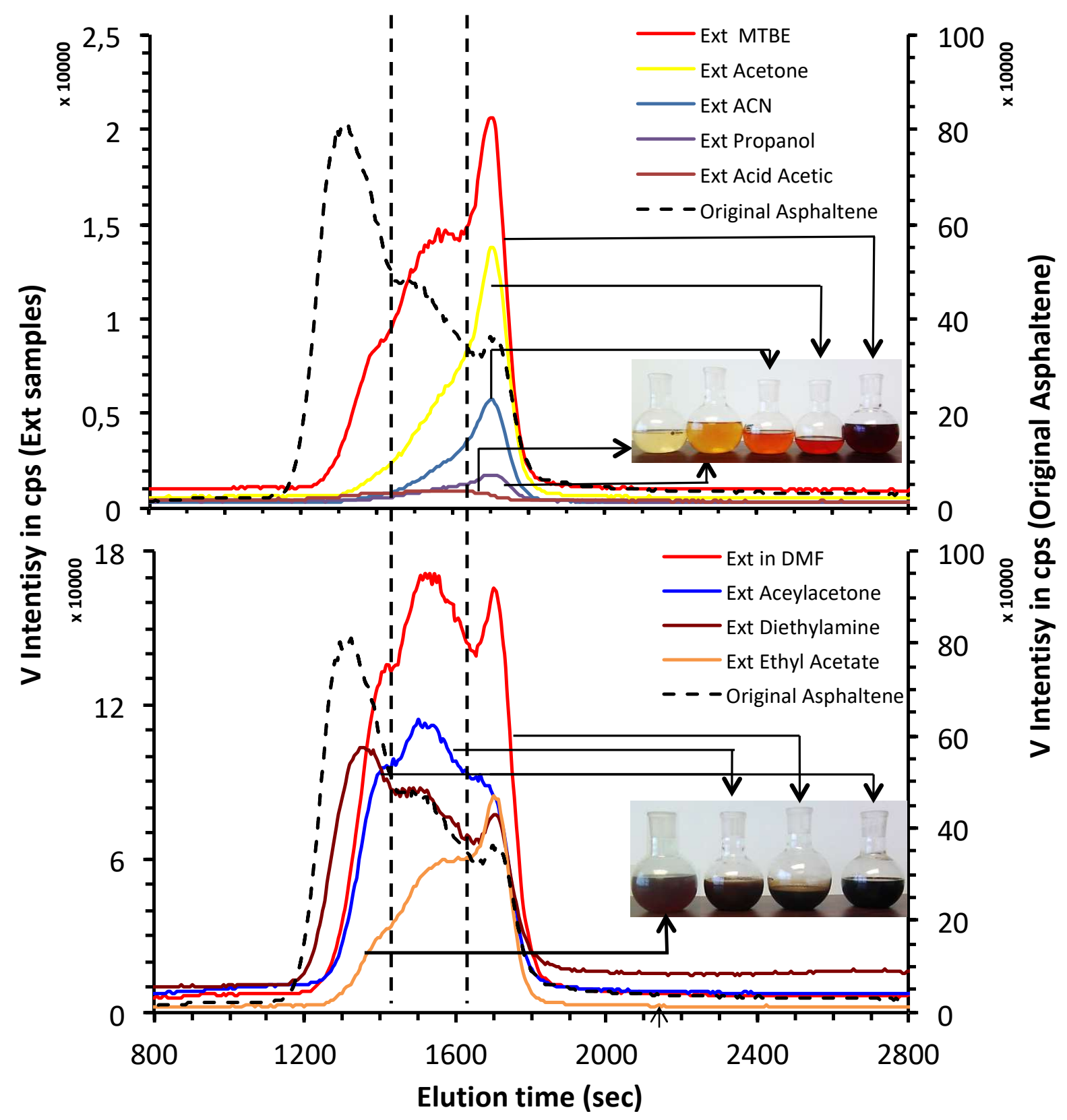

Figure 1. GPC-ICP MS profiles of the V compounds in the asphaltene extracts obtained with different solvents and with heating 


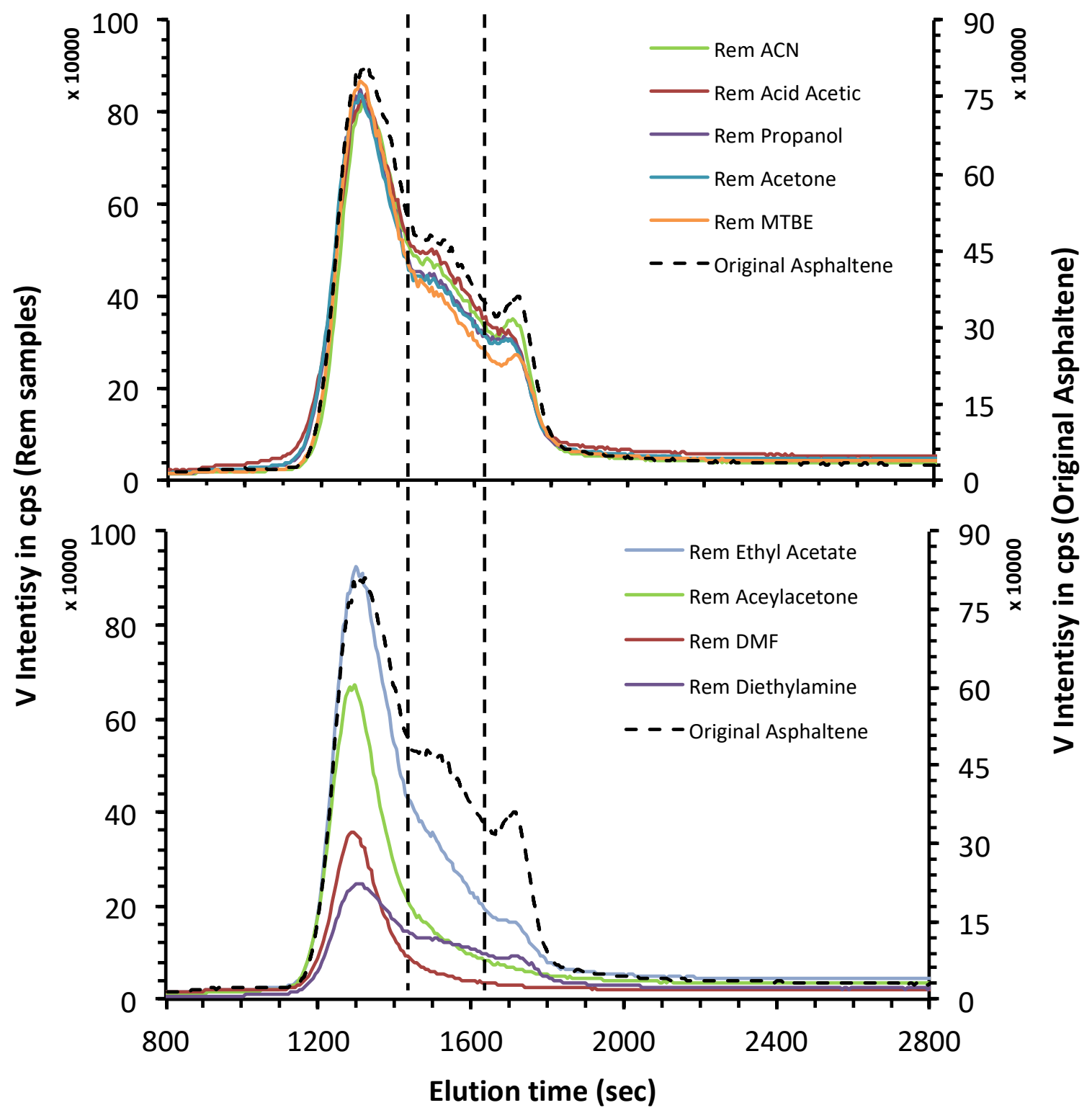

Figure 2. GPC-ICP MS profiles of the remanent V compounds in asphaltenes obtained with different solvents and with heating. 


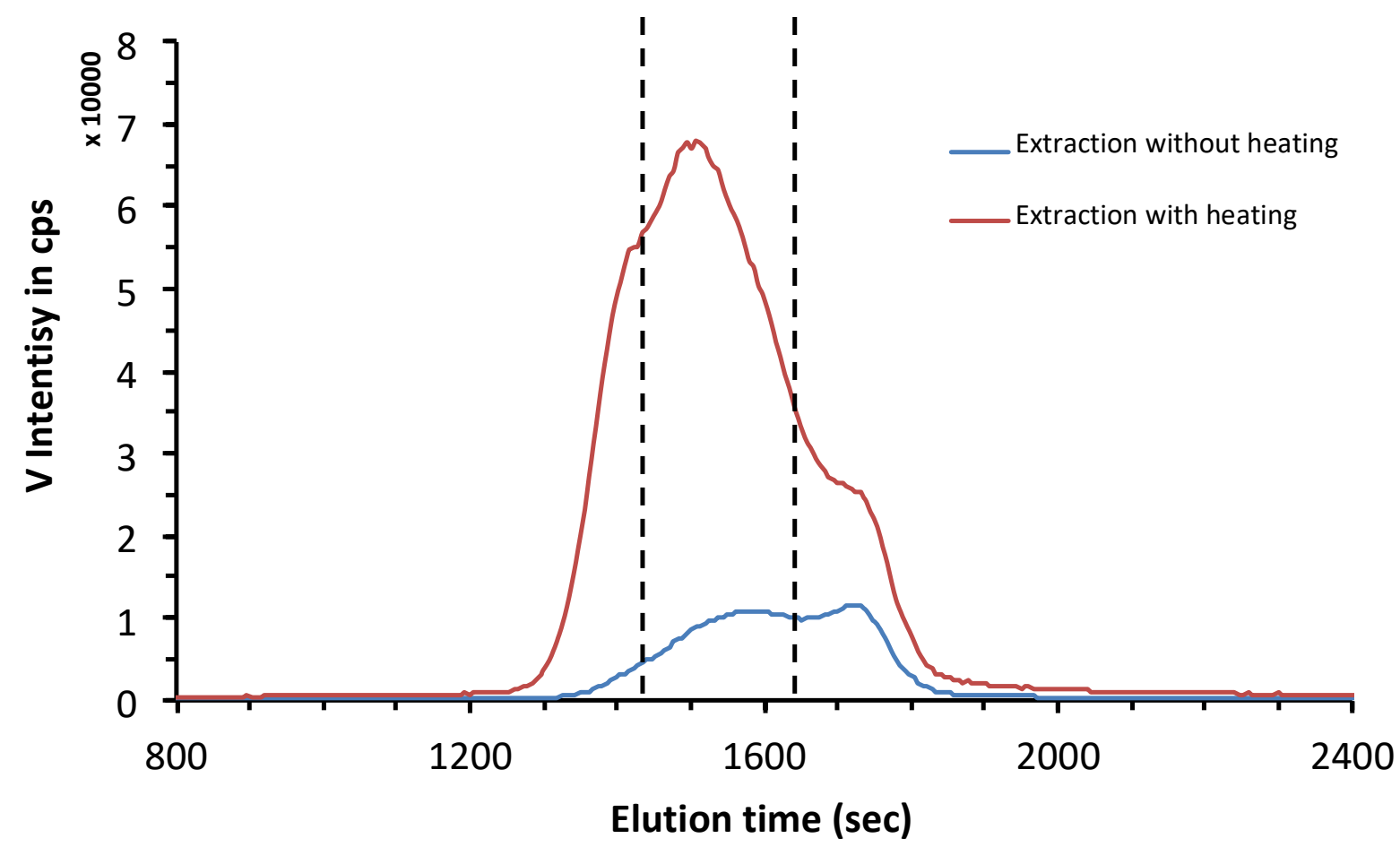

Figure 3. Comparison of the GPC-ICP MS profiles for DMF extractions with and without heating of the asphaltenes. 


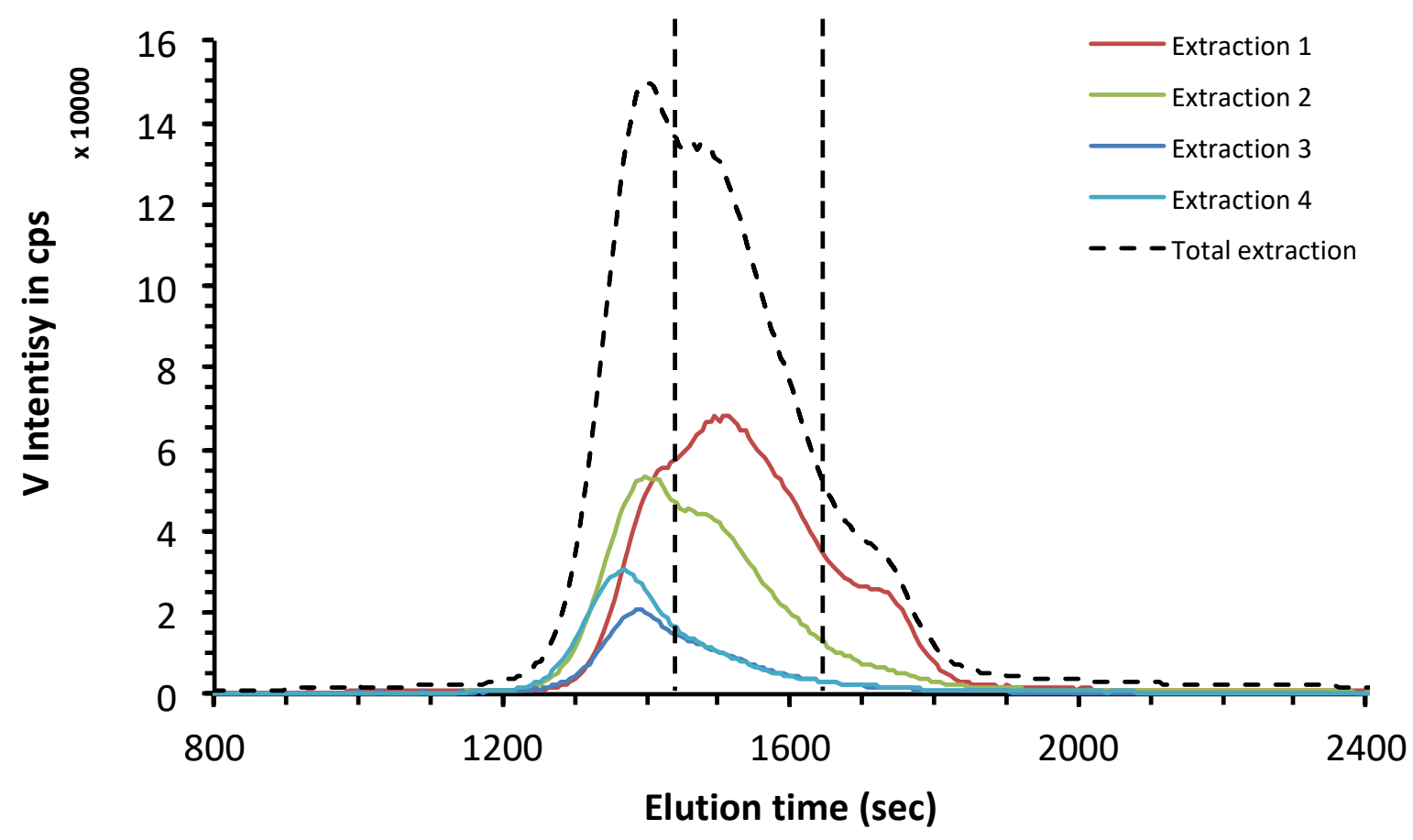

Figure 4. GPC-ICP MS profiles of the V compounds after 4 successive extractions of the asphaltenes with DMF. 


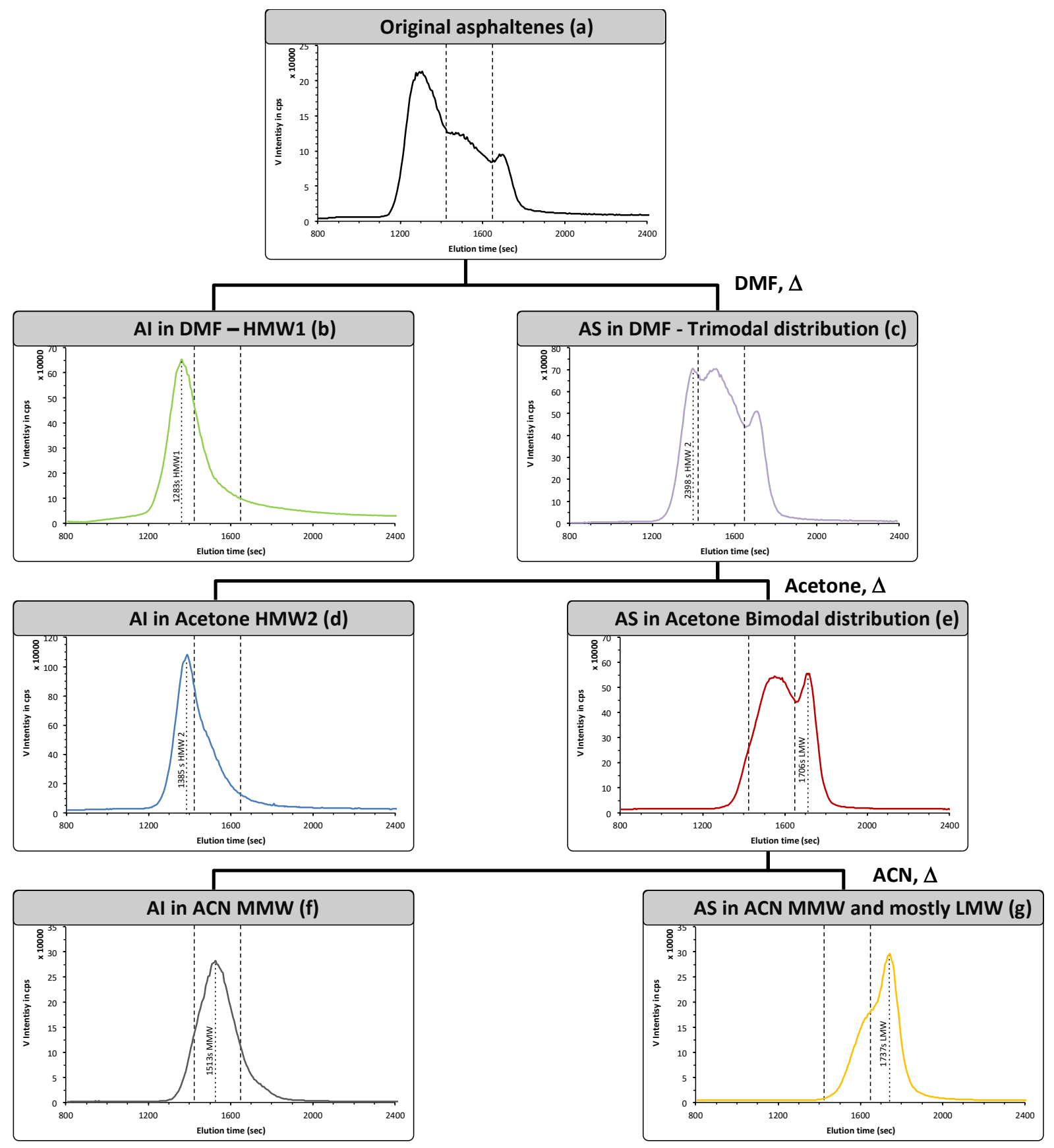

Figure 5. GPC-ICP MS profiles of the V compounds obtained with the optimum extraction scheme for the a) original asphaltenes, b) AI in DMF, c) AS in DMF, d) AI in acetone, e) AS in acetone, $\mathrm{f}) \mathrm{AI}$ in $\mathrm{ACN}$, and g) $\mathrm{AS}$ in $\mathrm{ACN}$. 

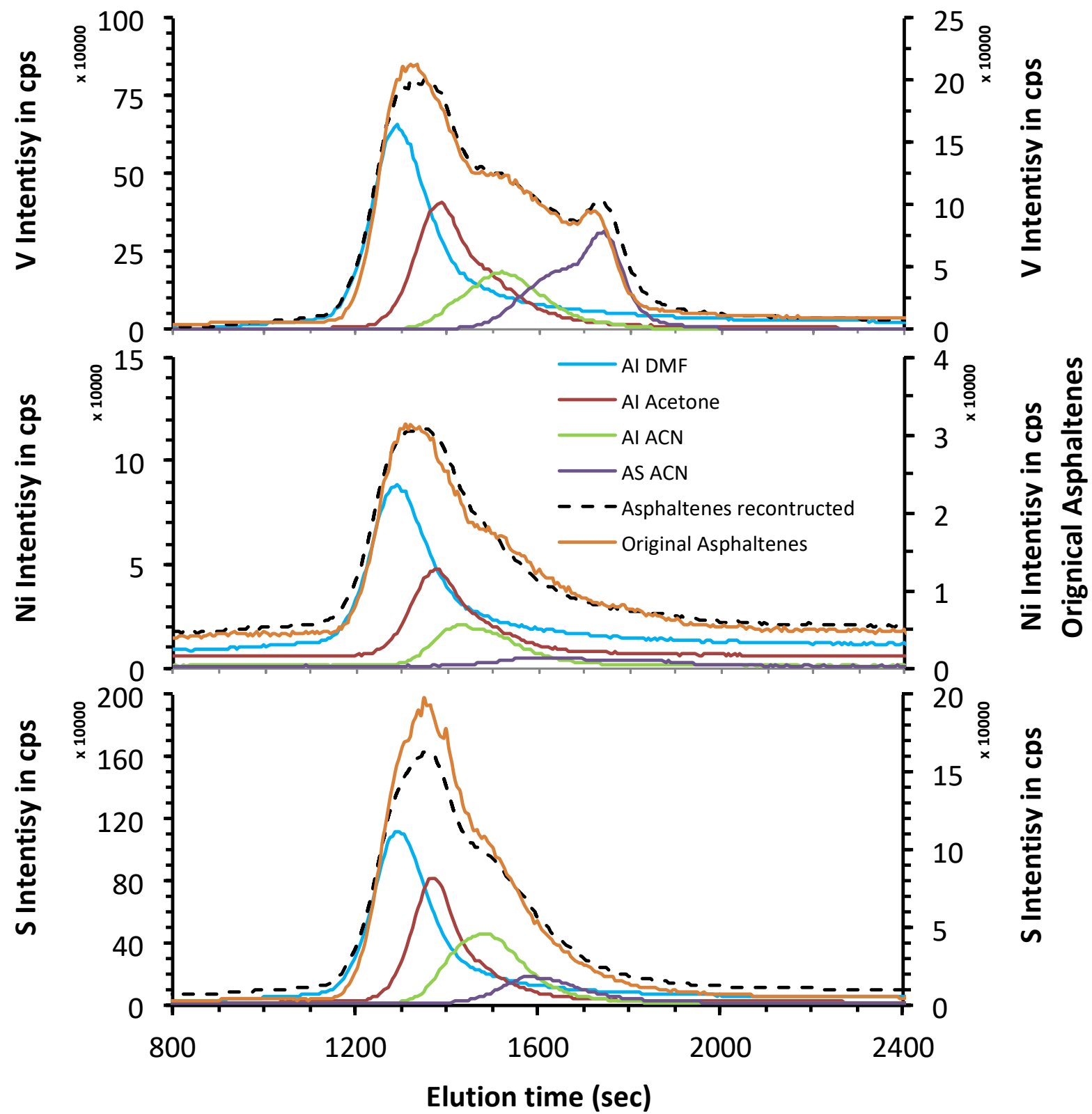

Figure 6. GPC-ICP MS profiles of the V, Ni and $\mathrm{S}$ compounds obtained for all asphaltene extracts. 


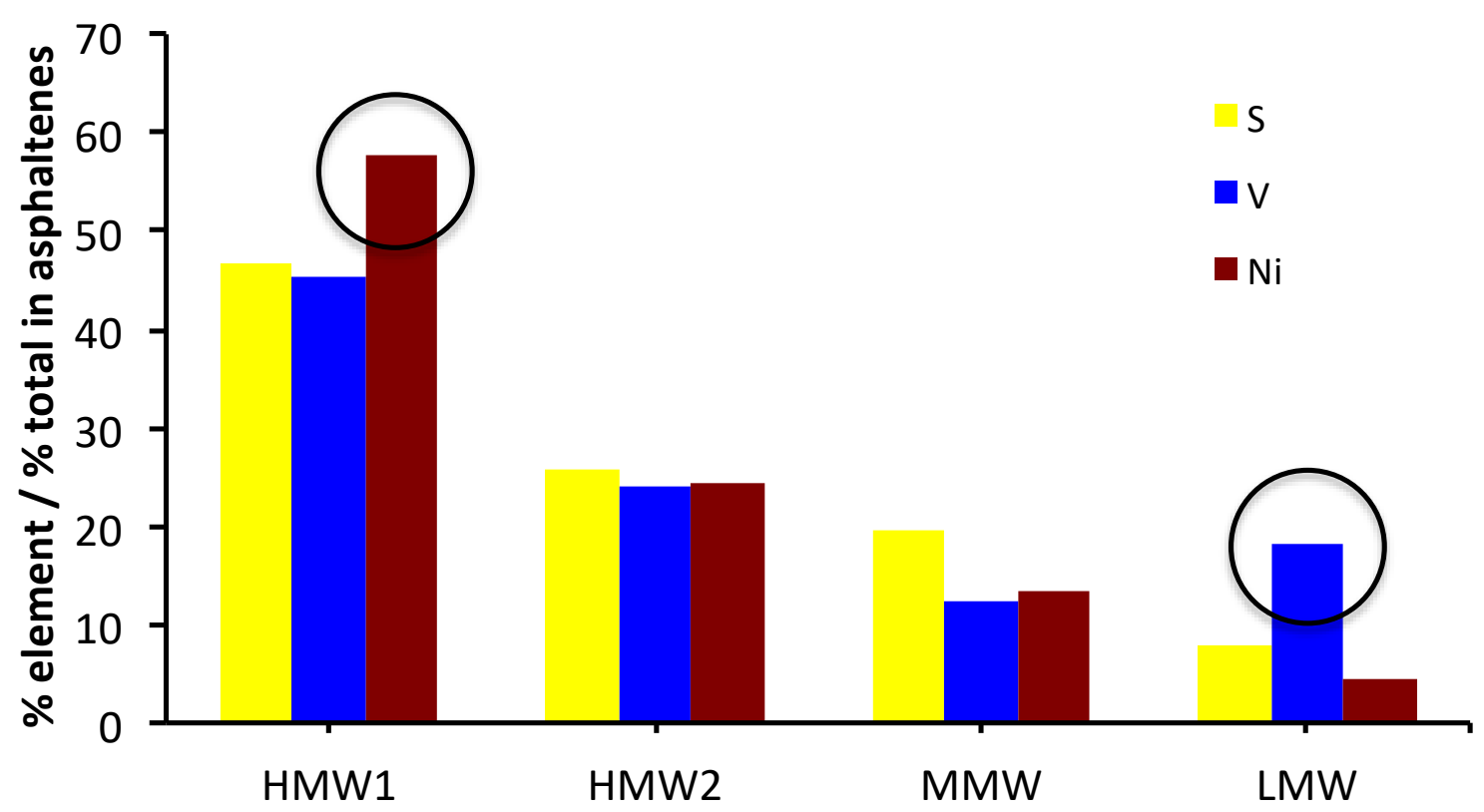

Figure 7. Percentage distributions of the $\mathrm{V}, \mathrm{Ni}$ and $\mathrm{S}$ compounds in the separated fractions of the asphaltenes. 


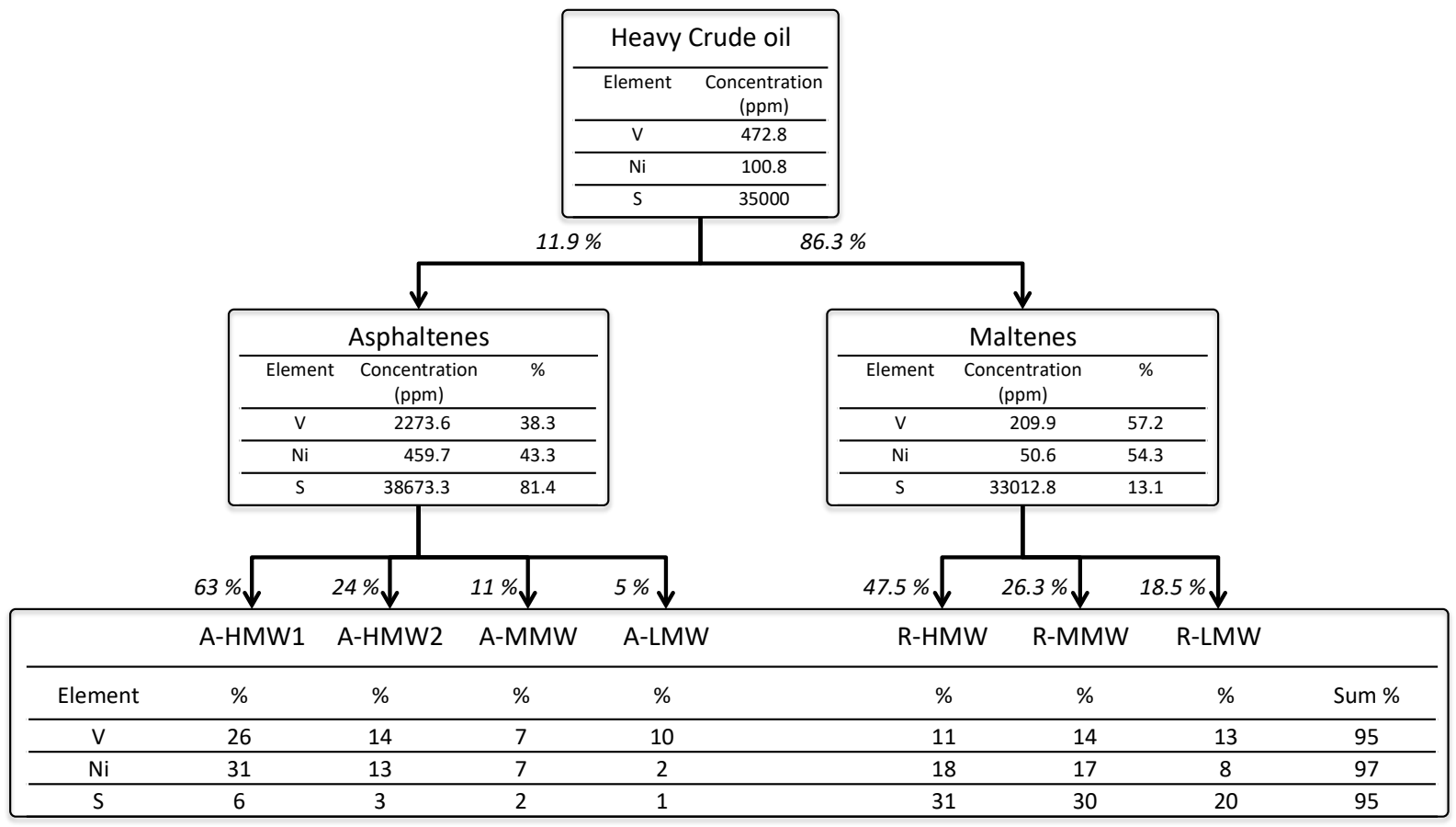

Figure 8. Complete fractionation process according to this study and a previous paper. ${ }^{47}$ 


\section{Table Caption}

Table 1. Mass percentages of the AS and AI fractions and several physical characteristics of the solvents that were evaluated.

\section{Figures Caption}

Figure 1. GPC-ICP MS profiles of the V compounds in the asphaltene extracts obtained with different solvents and with heating.

Figure 2. GPC-ICP MS profiles of the remanent V compounds in asphaltenes obtained with different solvents and with heating.

Figure 3. Comparison of the GPC-ICP MS profiles for DMF extractions with and without heating of the asphaltenes.

Figure 4. GPC-ICP MS profiles of the V compounds after 4 successive extractions of the asphaltenes with DMF.

Figure 5. GPC-ICP MS profiles of the V compounds obtained with the optimum extraction scheme for the a) original asphaltenes, b) AI in DMF, c) AS in DMF, d) AI in acetone, e) AS in acetone, $\mathrm{f}) \mathrm{AI}$ in $\mathrm{ACN}$, and g) $\mathrm{AS}$ in $\mathrm{ACN}$.

Figure 6. GPC-ICP MS profiles of the V, Ni and $\mathrm{S}$ compounds obtained for all asphaltene extracts.

Figure 7. Percentage distributions of the $\mathrm{V}, \mathrm{Ni}$ and $\mathrm{S}$ compounds in the separated fractions of the asphaltenes.

Figure 8. Complete fractionation process according to this study and a previous paper. ${ }^{47}$ 